\title{
Die Opskrifte van die Profeteboeke I
}

\author{
J P OBERHOLZER
}

1. Wat die vorm betref, kan die opskrifte van die profeteboeke ingedeel word in enkele hoofgroepe. Die indeling kan geskied aan die hand van die kernopskrifte of aan die hand van die formules vir openbaringsontvangs, of ook aan die hand van die dateringsformules.

2. Die kernopskrifte lewer die volgende indeling:

2.1. Dibrē gevolg deur die naam van die profeet: Amos en Jeremia met as parallelle die opskrifte van Prediker 1:1; Spreuke 30:1; 31:1; Nehemia 1:1.

2.2. $H^{a} z \overline{o n}$ gevolg deur die naam van die profeet: Jesaja en Obadja, met Nahum se 2de opskrif in die vorm sêfèr $h^{a} z \bar{z}$ nahum.

2.3. Debar yhwh gevolg deur 'n relatiefsin Hosea 1:1; Joël 1:1; Miga 1:1; Sefanja 1:1, met as latere vorms Sagaria 9:1; 12:1; Maleagi 1:1 waar $d^{e} b a r$ y hwh bystelling by maśśa is, Jeremia $1: 1$ waar dit deel van die openbaringsformule is en Ester 1:1-3; Haggai 1:1; Sagaria 1:1 waar debar yhwh nie kernopskrif is nie, maar subjek van 'n werkwoordelike sin, voorafgegaan deur'n datum.

2.4. Haddāāar gevolg deur 'n relatiefsin Jesaja $2: 1$ en Jeremia 7:1; $11: 1 ; 18: 1 ; 30: 1 ; 21: 1 ; 25: 1 ; 32: 1 ; 34: 1,8 ; 35: 1 ; 40: 1 ; 44: 1 ; 45: 1 ; 46: 13$; $50: 1$. Hiervan is Jesaja 2:1 en Jeremia $50: 1$ volwaardige boekopskrifte. Die res word deur lēmōr, 'n presiese tydsaanduiding of 'n eksklusiewe adressaat aangedui as opskrifte van die gedeeltes wat direk daarop volg, en vorm variasies van die profetiese inleidingsformules.

2.5. Maśśa gevolg deur 'n bystelling debar yhwh Sagaria 9:1; 12:1; Maleagi 1:1. Die opskrif van Spreuke 31:1 is hier 'n moontlike parallel, met maśśä voorafgegaan deur dibrẽ lemū'êt mèlèk, en gevolg deur 'n relatiefsin.

2.5.1. Maśśa gevolg deur die naam van die volk teen wie die uitspraak gerig is: Jesaja $13: 1 ; 15: 1 ; 17: 1 ; 19: 1 ; 21: 1,11,13 ; 22: 1 ; 23: 1$; 30:6; Nahum 1:1. Hiervan is net Jesaja 13:1 en Nahum 1:1 uitgebrei tot volwaardige boekopskrifte. Die ander is opskrifte van kleiner eenhede, en is blykbaar van die begin af so bedoel.

2.5.2. Hammaśśá gevolg deur 'n relatiefsin Habakuk 1:1. Hier dien as parallel Spreuke 30:1 waar hammaśśa bystelling is by dibrē 'agūr ben-yäkè.

3. Die formules vir openbaringsontvangs vertoon minder variasie:

3.1. 'ášèr hāzāa, voorafgegaan deur dibrē camōs Amos 1:1, hazōn

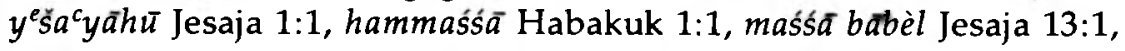


haddābār Jesaja 2:1. By Miga volg 'ǎšér hāāā as tweede relatiefsin op $d^{e} b a r$ yhwh, en staan dit parallel aan 'ǎšèr hāyā Miga 1:1.

3.2. 'ăšèr hāy $\bar{a}$, voorafgegaan deur $d^{e} b a r$ yhwh Hosea 1:1; Miga 1:1; Sefanja 1:1; Joël 1:1. In die perikoopopskrifte by Jeremia kom hierdie formule dikwels voor, voorafgegaan deur haddābār Jeremia 7:1; 11:1; $18: 1 ; 21: 1 ; 25: 1 ; 30: 1 ; 32: 1 ; 34: 1,8 ; 35: 1 ; 40: 1 ; 44: 1$. 'n Wisseling van die formule by Jeremia is verder'ášèr hayya $d^{e} b a r$ yhwh wat in Jeremia 1:2 op dibre yirm ${ }^{e}$ yahu volg en elders sonder enige antesedent as aanvangswoorde optree Jeremia $14: 1 ; 46: 1 ; 47: 1 ; 49: 34 \mathrm{vgl}$ I Konings 18:31. In Esegiël 1:3; Haggai 1:1; 2:1; 2:10; Sagaria 1:1, 7; 7:1 verskyn die formule as hăya $d^{e} b a r y h w h$, dus nie in a relatiefsin nie.

3.3. 'äšèr dibbér yhwh kom in perikoopopskrifte by Jeremia voor, voorafgegaan deur haddābār 44:16; 45:1; 46:13 en ook in die volwaardige opskrif 50:1.

Samevattend blyk dit dus dat met Jeremia ons by 'n oorganstadium verkeer ook wat die formule vir openbaringsontvangs betref.

4. Dieselfde blyk ten opsigte van die dateringsformules, wat by die vooreksiliese profeteboeke steeds dieselfde is, by Jeremia 'n oorgangsvorm vertoon, en in die eksiliese en na-eksiliese boeke ' $n$ nuwe vorm aanneem.

4.1. $b \bar{i} \bar{e}$ gevolg deur die naam en ampsaanduiding van een of meer konings Amos 1:1; Hosea 1:1; Jesaja 1:1; Miga 1:1; Sefanja 1:1; Jeremia 1:1 (Joël, Obadja en Nahum het geen daterings nie). By Amos en Hosea het ons dubbele daterings aan die hand van Israelitiese sowel as Judese konings: $b \bar{i} \bar{e} \bar{e} \ldots \bar{u} b \bar{t} m \bar{e} \ldots$ Hierdie daterings is algemeen van aard en omvat telkens ' $n$ betreklik groot tydperk.

4.2. ' $n$ Meer noukeurige datering kom voor in die uitbreiding van die Jeremia-opskrif waar die algemene datering "tydens Josia benAmon, koning van Juda" volg: "in die 13de jaar van sy regering, en dit het gebeur in die tyd van Jojakim ben-Josia, koning van Juda, tot aan die einde van die 11de jaar van Sedekia ben-Josia, koning van Juda, tot met die wegvoering van Jerusalem in die 5de maand." Reeds by Jesaja vind ons ' $n$ neiging tot noukeuriger datering van openbaringsontvangste bv. die datering van die roepingsvisioen in die sterfjaar van Ussia (6:1), dié van 'n masśśa in die sterfjaar van Agas (14:28), en dié van die opdrag tot 'n simboliese handeling in die jaar toe die tartan Asdod ingeneem het (20:1). In Jeremia vind ons daterings van uitsprake op openbaringsontvangste aan die hand van die soveelste jaar van konings $(25: 1 ; 32: 1 ; 36: 1 ; 45: 1)$ en dikwels aan die hand van gebeurtenisse $(21: 1 ; 34: 1,8 ; 40: 1 ; 28: 12 ; 36: 27 ; 33: 1)$. Van hierdie vorm van meer noukeurige datering van openbaringsontvangs is die oudste voorbeeld natuurlik dié in die Amos-opskrif: "twee jaar voor die aardbewing".

4.3. Die noukeurige datum met jaar, maand en dag tref ons aan in Esegiël $1: 1,2 ; 8: 1 ; 20: 1 ; 24: 1 ; 26: 1 ; 29: 1,17 ; 30: 20 ; 31: 1 ; 32: 1,17$; 
3ง:21; 40:1; Haggai 1:1, 15; 2:10; Sagaria 1:1, 7; 7:1. Hierdie wyse van çatering veronderstel ' $n$ betreklike nabyheid aan die gebeurtenisse, en het parallelle in die datering van die begin van die beleëring (Jeremia 52:4 vgl 39:1) en die val van Jerusalem (Jeremia 39:2; 52:12), die verheffing van jojagin (II Korings 25:27; Jeremia 52:31), en die vertrek uit Babel en aankoms in Jerusalem van Esra en sy geselskap (Esra 7:7-9). In buite-Bybelse tekste tref ons hierdie dateringswyse dikwels aan nie alleen in koningsannale en historiese tekste nie, maar ook in verhale, regsrapporte, verdrae, orakels, en briewe. Die datering van die vertrek van Israel van Sinai af (Numeri 10:11), die dood van Aäron (Numeri 33:38) en Moses se afskeidsrede aan die volk (Deuteronomium 1:3) is op dieselfde ratroon. Belangrik vir ons doel is egter die datering van openbaringsontvangs wat in een geval vir Moses by wyse van jaartal en in een geval by wyse van jaar en maand aangegee w ord (Numeri 1:1; 9:1) terwyl ook vir Elia 'n jaartal genoem word (I Konings 18:1).

5. As eerste resultaat van die klassifikasie volgens die vormelemente kernsopskrif, formule vir openbaringsontvangs en datering, kan ons noem dat daar ' $n$ duidelike vormverskil bestaan tussen die opskrifte van voor-eksiliese profeteboeke en eksiliese en na-eksiliese boeke, met dié van Ieremia as tussenstadium. As suiwer profetiese vorms kan uitgewys word die $h^{a} z \bar{n} n$ en $d^{e} b a r$ yhwh groepe, terwyl die dibré en maśśä-groepe verband met wysheidsboeke en met die gedenkskrif van Nehemia vertoon.

6. Hierdie resultaat word bevestig by beskouing van die ander vormelemente.

6.1.1. Die wyse waarop die adres van die Godswoord geformuleer word, hang saam met die aard van die formule vir openbaringsontvangs. 'ǎšèr hạ̄za word konstant gevolg deur die preposisie ${ }^{c} a l:{ }^{c} a l-$ yiśră'êt Amos 1:1, 'al-yehūdā wirušăläim Jesaja 1:1; 2:1, 'cal šōmrōn wirušăläim Miga 1:1. Om die konnotasie van 'al hier te bepaal, is nie so eenvoudig nie. Daarin lê sekerlik die betekenis "wat betref, oor", maar die nuansering "teen" is steeds daarby.

6,1.2. By die d'bar yhwh-groep wat gevolg word deur die formule 'ăšèr hāya is die preposie gewoonlik'èl, en is die profeet die eerste adres van die woord: Hosea 1:1; Miga 1:1; Sefanja 1:1; Joël 1:1. Dit geld ook die gewysigde vorms 'ǎšèr hāya de bar yhwh by Jeremia (1:2; $14: 1 ; 46: 1 ; 47: 1 ; 49: 34)$ en die vervolgsin tipes by Esegiël 1:3; Haggai 2:10; Sagaria 1:1, 7; 7:1. Ook die haddābār 'ášèr hãyā en die haddābār 'ášèr dibbèr word gevolg deur'èl en die naam van die profeet. Die een geval waar ' $a l$ hier voorkom, Jeremia $25: 1$, is dit' $n$ variant van èl. In Jeremia 50:1 word daar egter van dié patroon afgewyk met die formulering haddabār 'ăšèr dibbèr yhwh 'èl-Bäbèl 'èl-'èrès kasdîn be yad yirm ${ }^{e} y \bar{h} h \bar{u}$. Soortgelyke formulerings het ons in Haggai $1: 1 ; 2: 1$; 
Maleagi 1:1. Hier is die woord dus direk tot 'n volk of persone gerig en word die profeet duidelik as bemiddelaar aangedui.

Maśśá word in stat cstr verbind met die naam van die instansie waarteen dit gerig is behalwe in Jesaja 21:13; 30:6 waar in albei gevalle die preposisie $b^{e}$ gebruik word.

6.2. Biografiese besonderhede by die naam van die profeet bestaan uit:

6.2.1. Die genealogie van die profeet, meesal teruggevoer tot die vader (Hosea 1:1, Jesaja 1:1; 2:1; 13:1; Jeremia 1:1; Esegiël 1:1; Joël $1: 1)$, by Sagaria 1:1 twee geslagte terug en by Sefanja vier geslagte terug. By Amos, Obadja, Miga, Nahum, Habakuk, Haggai, Maleagi ontbreek die genealogie in geheel. Daaruit word dikwels afgelei dat die betrokke profeet van nederige stand was, maar dit geskied ten onregte, want die vadernaam het in baie gevalle saamgegroei met die eienaam tot 'n geheel, en waar dit ontbreek, kan daar baie verskillende redes voor wees. Die terugvoer van die genealogie verder as die vader is veral 'n kenmerk van eksiliese en na-eksiliese tyd. Dié genealogiese belangstelling het dikwels' $n$ aanwysbare motief, maar is nie noodwendig ' $n$ aanduiding dat die laaste naam in die ry ' $n$ uitsonderlike persoonlikheid aandui nie. Dit skyn wel of persone met'n genealogie verder terug as die vader tot die middestand behoort het. In die opskrifte van die Egiptiese wysheidsboeke ontbreek die vadernaam by Meri-ka-re, Amen-em-het, albei konings; ook by Hordedef, "Hereditary Prince and Count", en Ptah-Hotep, "Mayor and Vizier", terwyl dit wel voorkom by Amen-em-opet, ' $n$ mindere amptenaar (net vadernaam).

6.2.2. Die ampsaanduiding kom voor by Amos, Jeremia 1:1; 50:1; Esegiël, Habakuk, Haggai, Sagaria

6.2.2.1. Die mees algemene ampsaanduiding is hannābi, wat in die opskrifte Jeremia 50:1; Habakuk 1:1. Haggai 1:1 en Sagaria 1:1, 7 voorkom, en verder binne enkele profeteboeke nog telkens voorkom as byskrifte by die naam van die profeet, wat homself, terloops, nooit so noem nie (Jesaja $37: 2 ; 38: 1 ; 39: 3$; Jeremia $1: 5 ; 20: 2 ; 25: 2$; $28: 5,6,10,12,11,15 ; 29: 1,29 ; 34: 6 ; 36: 8,26 ; 37: 2,3,6,13 ; 38: 9,10$, $14 ; 42: 2,4 ; 43: 6 ; 45: 1 ; 46: 1,13 ; 47: 1 ; 49: 34 ; 50 \cdot 1 ; 51: 59$; Habakuk $1: 3,12 ; 2: 1,10$ ).

6.2.2.2. Esegiël en Jeremia word as priesters aangedui, Esegiël direk as hakkōhēn en Jeremia as minhakkōhhānim 'äšèr bacănätot be'èrèș binayamin. Dat Jeremia die presteramp ooit bedien het, lyk baie onwaarskynlik. Van Esegiël kan dit wel aangeneem word, mede as gevolg van die inhoud van sy boek.

6.2.2.3. Amos het as byskrif by sy naam 'áš̀r hâya ã bannōq $q^{e}$ dim mit$t^{e}$ qoa. Ten spyte van alle pogings om Amos tot boer uitsluitlik te verklaar, sal die kultiese interpretasie van hierdie woorde homself altyd weer na vore dring vanweë die ongewone konstruksie en die onse- 
kerheid oor die betekenis van nōqe्d, wat deur LXX sowel in II Konings 3:4 as Amos 1:1 bloot getranskribeer word.

Die getuienis van 7:10-17 is dat hy uit Juda afkomstig was, homself nie as nabi beskou het nie, maar'n boer was wat sy roeping midde in die boerdery ontvang het. Dit sluit egter nie uit dat hy op een of ander wyse, voor of na sy profetiese optrede, kon behoort het tot die $n \overline{o q} q^{e} \bar{d} \bar{m}$ wat uit Tekoa afkomstig was en na Akkadiese voorbeeld in diens van die tempel kan gestaan het nie. Afdoende bewysgronde vir so 'n opvatting het nog nie te voorskyn gekom nie. Intussen bly Amos dus ' $n$ boer wat vir' $n$ kort tydjie as profeet opgetree het, en bly hierdie element in die opskrif van sy boek uitsonderlik, vergeleke by die ander profeteboeke.

Dit kom voor of ampsaanduiding 'n betreklik vaste bestanddeel in die opskrifte of inleidings van geskrifte in die ONO was: Sinuhe word aangedui as "The heriditary Prince and Count, Judge and District Overseer of the domains of the Sovereign in the lands of the Asiatics, real acqaintance of the king, his beloved, the attendant Sinuhe" (oudste ms $1800 \mathrm{vC}$ ); Wen-Amon as "the Senior of the forecourt of the House of Amon" (11de eeu vC); Ptah-Hotep as "Mayor and Vizier" (Middelryk); Hor-dedef as "Hereditary Prince and Count, the King's Son" (1250-1150 vC); terwyl Amen-em-opet 'n hele reeks ampte besit het, w.o. "Overseer of the Soil, Overseer of Grains" en "Scribe" (7-6de eeu). Die outeur van die sg. "Satire on the Trades". Khety, word genoem "a man of the ship's cabin". In Hetitiese rituele tekste kom ook nog voor die titels "Arzawa-man" en "Arzawa-vrou" (vgl ANET).

In die lig hiervan kan die ampsaanduidinge in die profeteopskrifte nie ligtelik as sekondêre toevoegings beskou word nie, ook nie dié van Amos nie.

6.2.3. Die aanduiding van die plek van herkoms kom net in 4 gevalle voor, nl by Amos, Miga, Nahum, Jeremia. By Amos en Jeremia geskied dit tesame met die beroepsaanduiding, by Miga en Nahum as gentilicia. Die nader identifikasie van ' $n$ persoon deur die bystelling van ' $n$ gentilicium by sy naam is in die Ou Testament' $n$ heel gewone verskynsel vgl Joas die Abiësriet (Rigters 6:11), die helde van Dawid (II Samuel 23:8, 9, 11, 25-39) ens. So ook die gebruik van die prep. min by die pleknaam (II Samuel 23:20, 24, 29). Die plek van herkoms by Amos en Nahum word nie elders betuig nie, dié van Miga in Jeremia 26:18 en dié van Jeremia in sy eie boek. Minstens by Amos en Nahum en miskien ook by Miga en Jeremia het ons te doen met oorspronklike opgawes, want dié van Miga berus by Jeremia 26:18 duidelik op die gegewens van Miga, en dié van Jeremia is deel van 'n sin waarvan die eerste deel ook oorspronklik moet wees. 


\section{Die debar jhwh-groep:}

Hosea 1:1 d debar-yhwh 'ǎšèr hāyā 'èl-hōšéca bèn- $b^{e ' e ̄ r i ̄ ~ b i m e ~ . . . ~}$ Joěl 1:1 debar-yhwh 'ǎšèr hāyā 'èl-yo'êl bèn-petū'ēl

Miga 1:1 debar-yhwh 'ǎšèr hãyā 'èl-mika hammōrasti bimē . . . ǎšèr hāzā cal ...

Sefanja 1:1 $\mathrm{d}^{\mathrm{e}}$ bar-yhwh 'ǎšĕr hāyā 'èl-s ${ }^{e}$ fanyā bèn-kūšš bèn $\ldots$ bèn $\ldots$ bèn $\ldots$ bìmē $\ldots$

Die gelykluidendheid van hierdie opskrifte dui op 'n gemeenskaplike herkoms, 'n redaksie van die hand van 'n persoon of persone wat die betrokke boeke gewaardeer het as $d^{e} b a r y h w h$. Vriezen (Hoofdlijnen) wys daarop dat die uitdrukking $d^{e} b a r$ yhwh oorspronklik en in eintlike sin alleen 'n direkte deur die profete oorgebringde Godspraak aangedui het, en daarom in die eerste tyd ook slegs gebruik is vir 'n geskrif met Godsprake waarin geen, of so goed as geen ander elemente voorkom nie. Daarop vorm dan Hosea 1 en 3, Joël 2:18, 19 en Miga 3:1a klein uitsonderings. Vriezen beskou dan ook as baie waarskynlik die opvatting van Budde dat in Joël en Miga verhalende stukke geskrap is omdat die versamelaars wat die boeke as debar yhwh aangedui het, geen verhale en toevoegings wou toelaat wat nie direkte Godswoorde was nie, en neem aan dat dit die rede kan wees waarom dergelike opskrifte nie vir groter profetiese versamelings soos Jesaja, Jeremia en Esegiĕl gekies is nie, omdat die versamelaars sou besef het dat hier veel meer as net Godswoorde in gestaan het. Hieruit wil dit voorkom of Vriezen 'n gemeenskaplike opskrif-redaksie vir die profeteboeke aanvaar, waarby dan opskrifte vir die boeke gekies is aan die hand van hulle onderskeie inhoude. Dan word egter die formules vir openbaringsontvangs in die dibré- en $h^{a} z \overline{o n}$-groepe problematies, want daardeur word die woorde of gesig van die profeet, wat dan die hele boek tipeer, ook op die goddelike openbaring teruggevoer. Veeleer het Procksch gelyk as hy beweer dat die $d^{e} b a r-$ $y h w h$-groep jonger as die $h^{a} z \bar{o} n$ en dibré-groepe is, wat die profeet as outeur aandui. Miskien is dit dus só dat ons in die debar-yhwh-groep te doen het met opskrifte wat ouer opskrifte vervang het of uitgebrei het. In die geval van Joël, Miga en Sefanja moet ons daarmee rekening hou dat die name van die profete en hulle biografiese besonderhede nie binne hulle boeke voorkom nie. Dié van Miga word wel genoem in Jeremia 26:18, gevolg deur aanhaling van een van sy profesieë. Die feit dat in Jeremia 26:18, 19 sowel die agtergrond as uitwerking van een van Miga se spreuke (3:12) aangedui word, 'n plus teenoor sy eie boek, wys in die rigting van 'n mondelinge oorlewering van die inhoud en geskiedenis van profetewoorde oor 'n lang tydperk. Tog lyk dit of die naam en herkoms van Miga deur die Jeremia-sitaat ontleen is aan ' $n$ opskrif van ' $n$ versameling Miga-woorde. Die tweede openbaringsformule in die Miga-opskrif, wat oor die algemeen as later toevoeging beskou word ('ášèr ḩāzō cal šōmrōn 
wirūšălāim), kom elders voor in Amos 1:1 (dibrē camōs) Jesaja 1:1 ( ha- $^{a}$ zōn), Jesaja 2:1 (haddābār), Jesaja 13:1; Habakuk 1:1 (maśśa). Die vraag kan gestel word of ons nie hier te doen het met die oorblyfsel van 'n

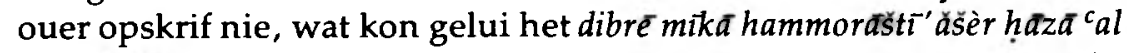
... bimē ... (Vgl nou Van der Woude, Micha, POT). Net so kom dit voor of die inleidingsformule in Hosea 1:2 $t^{e}$ hillat dibbèr-yhwh $b^{e} h \bar{o}-$ $\zeta \bar{e}^{\tau} a$ (wat ook gelees kan word $t^{e} h i l l a t ~ d a b b \overline{e r} / d^{e} b a r-y h w h$... saam met LXX en Syr) die oorspronklike opskrif van die boek of gedeelte daarvan kon gewees het, miskien met die vadernaam bèn-b $b^{e \prime} \bar{e} \bar{t}$ daarby. Dit lyk baie waarskynlik na analogie van die opskrifte van die Egiptiese wysheidsboeke van Meri-ka-re, Amen-em-het, Hor-dedef, Satire on the Trades and Divine Attributes of the Pharaoh, ("The beginning of the instruction which ..."), Amen-em-opet ("The beginning of the teaching of life ... made by ...), vgl. verder die Atum-mite (The beginning of exaltations and beatifications"), die Apophismite ("The beginning of the book of overthrowing Apophis ...). Dit lyk dus of die debar-yhwh-groep opskrifte verteenwoordig wat met 'n bepaalde opset aangebring is in die plek van of ter uitbreiding van ouer opskrifte. Daarby het die feit dat die betrokke boeke 'n minimum aan verhalende materiaal bevat, miskien 'n rol gespeel, maar dan vra die feit dat dieselfde die geval is met Obadja en Nahum, wat tog nie soortgelyke opskrifte gekry het nie, om verklaring. Dit wil dus eerder voorkom dat die oorspronklike opskrifte van Hosea, Joël, Miga en Sefanja of nie volledige boekopskrifte nie óf onaanvaarbaar was. Dit sou onaanvaarbaar wees as 'n boek wat uitsluitlik Godswoorde bevat, in sy opskrif as "Woorde" van die betrokke profeet aangedui gewees het, terwyl opskrifte soos dié van Obadja en Nahum ( $h^{a} z \bar{o} n$ en maśśã + sêfèr $h^{a} z \bar{n}$ ) nie aanstoot sou gegee het nie. Daar lê dus 'n teologiese motief in die aanduiding van hierdie vier boeke as debar $y h w h$. Dieselfde teologiese motief is te sien in enkele van die relatiefsinne in die opskrifte van ander profeteboeke. Die dibrē $c^{a m o ̄ s}$ word

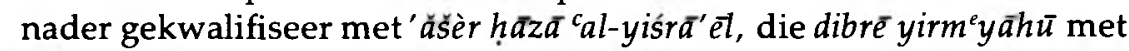
'ǎšèr hãyā d'bar yhwh 'elāw, die maśśa van Habakuk met 'ǎšèr hāāa $h^{a} b a q q \bar{u}$, vgl ook Jesaja 13:1. Alleen sou ons die aanbring van die $h \bar{a} z \bar{a}$-formules (afgesien van die Jesaja 13:1-een) ouer moet stel as die $h \bar{a} y \bar{a}$-formule by Jeremia. Die uitbreiding van die Jeremia-opskrif met die openbaringsformule en die aanbring van die opskrifte van Hosea, Miga, Sefanja en Joël moet dus van een hand of van agtereenvolgens nabootsende hande wees. Die boek Joël word feitlik algemeen in na-eksiliese tyd gedateer. Sy opskrif plaas hom egter in die ry van die voor-eksiliese boeke, wat vorm betref. Indien ons 'n gesamentlike redaksie van die vier boeke aanvaar, sou dit ons dus afbring tot einde 5 de eeu of selfs later. Dit lyk my egter meer waarskynlik dat ons vir Joël óf 'n agterna redaksie óf 'n vroeër ontstaanstyd met sterk latere bewerking moet aanvaar. Die d'bar yhwh-op- 
skrifte tesame met die openbaringsformules'ǎšèr hãyā'él skyn tuis te wees in die deuteronomistiese gedagtewêreld en kan daarom liefs in die ballingskap gedateer word, in dieselfde tyd toe die boek Jeremia in Babilonië sy eindgestalte gekry het. Dit is ' $n$ vraag of die datering van die betrokke boeke ook in hierdie tyd geskied het. Joẽl het geen datering nie, en behalwe Hosea, Miga en Sefanja het ook nog Amos, Jesaja 1:1 en Jeremia 1:1-3 daterings aan die hand van koningsheerskappye. Wat ons hier versigtig moet stem, is dat datering op hierdie wyse ook in boekopskrifte bv. die opskrif van pta-hotep (midderyk) in Egipte voorkom, en dat die formule bimē gevolg deur'n persoonsnaam baie oud is (vgl Rigters 5:6) binne die Ou Testament self. By Amos en Hosea sou dus die datering "in die tyd van Jerobeam benJoas, koning van Israel" deel kon wees van die oorspronklike opskrif, of dit kan op 'n later stadium aan hulle boeke ontleen gewees het, met ' $n$ later byvoeging van die sinkronisasie met Judese konings. Dieselfde reeks Judese konings as by Hosea word genoem in die opskrif van Jesaja en (met uitsondering van Ussia) ook in dié van Miga, en dit is moontlik dat die datering van Jesaja aan sy boeke ontleen kan wees. By Miga moes minstens die datering na die tyd van Hiskia oorspronklik gewees het (Jeremia 26:18, 19), maar omdat die ander twee konings (Jotam en Agas) ook nie in sy boek genoem word nie, is die dateringsformule waarskynlik ' $n$ eenheid.

\section{Die hazōn-groep}

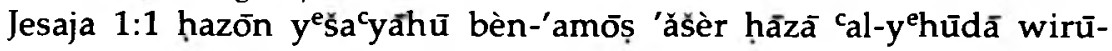
šãăìm bîmē ...

Obadja 1:1 hazōn cōbadyã

Nehemia 1:1 maśśā nīn ${ }^{e}$ wē sêfèr hạazōn nahưum hāè̀lqošī

Net soos by d'bar-yhwh die term vir die enkele Godswoord in betekenis uitgebrei is om die totaal van openbaring te omvat wat 'n profeet toegekom het, het ook hāazon 'n betekenisuitbreiding ondergaan toe dit in die boekopskrifte op die inhoud van die hele boek betrek is, en so ' $n$ algemene aanduiding van openbaring geword het. König (Theologie) het daarop gewys dat die profete hulle eie openbaringsontvangs van visioenêre aard altyd met $r \bar{a}^{\prime} \bar{a}$ aangedui het, en nooit met $h \bar{a} z \bar{a}$ nie. Jesaja gebruik bv. $r \bar{a}^{\prime} \bar{a}$ by sy roepingsvisioen (6:1). By Obadja en Nahum kom binne hulle boeke egter geen verwysing na 'n visioenêre belewenis voor nie. Tensy die teofanie aan die begin van Nahum dus aanleiding gegee het tot die keuse van die woord $h \bar{a} z \bar{o} n$, het ons hier te doen met $h \bar{a} \bar{z} \bar{o} n$ as woordopenbaring. Vriezen het aan die hand van Habakuk 2:1-5 geillustreer dat die gesig wat aan 'n profeet gegee is, juis ' $n$ woord kon wees. Wat Obadja en Nahum betref, kan die opskrifte dus nie aan die hand van die inhoud van die boeke gevorm gewees het nie, en die feit dat die Jesaja-opskrif(te) as

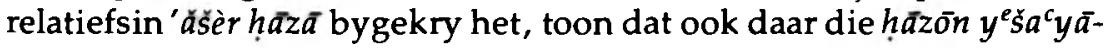


$h \bar{u}$ oorspronklik moet wees. By Jesaja het ons die probleem op watter deel van die boek die opskrif betrek kon gewees het. Duhm, gevolg deur Gray en Herntrich sien hăazon as aanduiding van 'n apokaliptiese interpretasie van die profesie uit na-eksiliese tyd en beskou 1:1 as opskrif van c1-12. Fohrer plaas dit vroegstens in eksiliese tyd, maar meen dat dit daar geplaas is deur die versamelaar van die wesenlike deel van c1-39. Vir die eksiliese tyd voer Fohrer as argumente aan die volgorde Juda-Jerusalem in die relatiefsin en die uitdrukking $h \bar{z} h$ h $\bar{a} z \bar{o} \bar{n}$ "visioen sien". Saam met Wildberger aanvaar ek dat Jesaja 1 as oorspronklike opskrif slegs die woorde hāazon $y^{e} \bar{s}^{c}{ }^{c} y \bar{a} h \bar{u}$ bèn'âmoṣ gehad het, en later uitgebrei is as opskrif van 1-39. Oorspronklik het die hazōn-groep dus kort opskrifte bokant kort profetiese geskrifte verteenwoordig. Die 'ášèr hăża ${ }^{c} a l$-uitbreiding het, wat Jesaja betref, geskied na analogie van die opskrif in Jesaja 2:1, wat as oudste van die drie Jesaja-opskrifte moet geld. Dergelike uitbreidings in die opskrifte van Amos en Habakuk moes kontemporêr met Jesaja 2:1 ontstaan het, dus tydens die ballingskap, maar waarskynlik vroeër as die $d^{e} b a r$-yhwh-groep. Die Nahum-opskrif het nog 'n sêfèr voor häzōn: "Die boek van die gesig van Nahum, die Elkoriet". Na aanleiding van die Boek van die oorloë van die Here (Numeri 21:14), die boek van Jasar (Josua 10:13; II Samuel 1:18) en die boek van die wet van Moses (Josua en passim) kan ons aanneem dat ons hier te doen het met ' $n$ werk wat van die begin af in geskrewe vorm was. Die eerste opskrif van Nahum maśśa $\operatorname{nin}^{e} w \bar{e}$ orden die profesie van Nahum onder die vreemdevolk-orakels soortgelyk aan dié in Jesaja, en het waarskynlik ontstaan na analogie van die Jesaja-opskrifte.

\section{Die dibrē-groep}

Amos 1:1 dibrēe camōs 'ǎšèr hāyā bannōq ${ }^{e} \operatorname{dīm}^{-} \operatorname{mitt}^{e}{ }^{e} \bar{o}^{-} a$

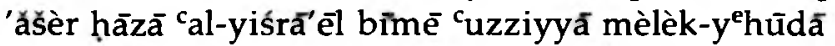

ūbīmē yārob ẫm bèn-yō'âš mèlèk yiśrâ'êl

šenātayim lifnē harẫ aš

Jeremia 1:1-3 dibrē yirm ${ }^{e}$ yãhū bèn-hiilqiyyãhū min-hakkōhãnīm 'ǎšèr bacănātōt

bè èrèș binyāmīn

'ǎšèr hāyā debar yhwh 'êlāw bīmē yōšiyyāhū

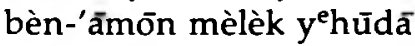

"in die 13de jaar van sy koningskap, en verder het dit gebeur tydens Jojakim ben-Josia, koning van Juda, en tot op die einde van die 11de jaar van Sedekia ben-Josia, koning van Juda, tot met die wegvoering van Jerusalem in die 5de maand".

Die ooreenkoms tussen hierdie twee opskrifte lê eintlik net in die aanhef en dié word deur LXX opgehef, wat vertaal to rèma tou Theou, ho egeneto epi leremian, en so die opskrif volkome in die $d^{e} b a r$-yhwh-groep plaas. Die LXX-weergawe berus duidelik op 'n 
ander Hebreeuse teks as Mass., en toon dat daar minstens in sekere kringe gepoog is om Jeremia se boek wat opskrif betref in lyn te bring met die $d^{e} b a r-y h w h$-groep. Amos en Jeremia toon egter ook verwantskap wat betref die biografiese besonderhede ten opsigte van beroep en plek van herkoms, in soverre dit by albei deur middel van ' $n$ bysin geskied. Ek het reeds gewys op die ooreenkoms van die kernopskrif dibrē gevolg deur die naam van die profeet met dié van wysheidsboeke in die Ou Testament en met Nehemia. Daarby kan ons voeg Ahiqar waarvan die geskonde aanhef herstel kan word tot "Die woorde van A hiqar" of "Hier volg die woorde van A hiqar..." soos in Spreuke 24:23. Hierdie opskrif dui dus die outeurskap van 'n boek aan, en as oorspronklike opskrif moet vir Amos aanvaar word dibrē camōs 'ášèr hãa ă bannōq ${ }^{e} d \bar{m}$ mitt ${ }^{e} \bar{o}^{c} a$ en vir Jeremia dibrē yir-

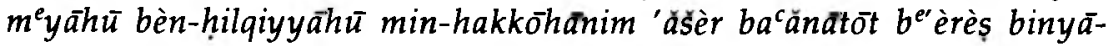
min. Dit beteken dus dat nie een van die boeke oorspronklik in hulle opskrifte enige teken van goddelike gesag gedra het nie, en dit dui daarop dat die opskrifte nie van die profete self afkomstig was nie, maar van persone wat hulle woorde (voorlopig) onder die eie name van die profete in bewaring wou hou. Daarop dui ook die manier waarop die biografiese gegewens ingeklee is, wat net sin maak as dit nié deur die profete self nie, en weg van Tekoa en Anatot, geskied het. Ons moet dus aanneem dat'n versameling Amoswoorde met die kort opskrif aanvanklik in Betel bewaar is, en wel by die tempel, die enigste plek waarvan ons weet waar dergelike geskrifte bewaar kon word, afgesien van die koninklike paleis (vgl Misjna Kelim 15.6, Parak 10.3, Zabim 5.12, Deuteronomium 31:9; Jesaja (30:8) 65:6; Deuteronomium 17:18; 31:26; I Samuel 10:25; II Konings 23:2, 3; 22:8, 10). Later, waarskynlik eers in die tyd van Josia se hervorming, is die boek, miskien saam met dié op Hosea, na Jerusalem geneem, maar nie voordat dit ' $n$ tweede redaksie ondergaan het in Betel nie, hierdie keer met ' $n$ herwaardering van Amos se woorde. Met hierdie redaksie is die oorspronklike opskrif uitgebrei met die woorde 'ăšèr hạzza

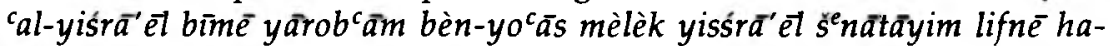
$r \bar{a} c a s$. Dit moes geskied het nadat dit geblyk het dat Amos se woorde eg profeties was. Dat dit ná die aardbewing gebeur het waarna Amos in $2: 13 \mathrm{vv} ; 3: 14 ; 9: 1$ as iets toekomstigs sou verwys, is 'n moontlikheid, maar die betrokke verwysings is geensins duidelik nie. Dit lyk meer waarskynlik dat die herwaardering van Amos se woorde kon geskied het ná die vervulling van sy profesie oor die einde van die noordelike ryk, en dat die nader datering van Amos se optrede as "twee jaar voor die aardbewing" op herinnering berus het. Die verdere en laaste uitbreiding van die opskrif is van Judese hand, waarskynlik tydens die ballingskap, toe die regeringstyd van Jerobeam die parallel in koning Ussia, wat voorop gestel is, gekry het.

Wat Jeremia betref, neem ons as eerste opskrif van 'n versameling 
van sy woorde wat deur Jerusalemse tempelpersoneel bewaar en na die val van die stad na Babel geneem is, aan die woorde: dibrē

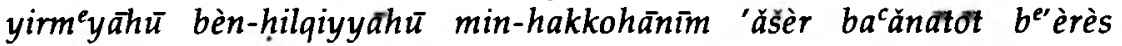
binyāmin. Hierdie opskrif moes nog in Jerusalem, voor die val van die stad, ontstaan het. $\mathrm{Na}$ die val van die stad en tempel is hierdie geskrif met ander saamgeneem na Babel, waar dit 'n uitbreiding in die opskrif ondergaan het wat die "Woorde van Jeremia" as vervulde openbaringswoord erken het: 'ăšèr hāy $\bar{a} d^{e} b a r-y h w h$ 'etāw bìmé yošiyyāhü bèn-'āmōn mèlèk $y^{e} h u \bar{d} a \bar{a}$. Die talle perikoopopskrifte in Jeremia dui op ' $n$ ingewikkelde proses van bewaring van kleiner eenhede, waarby die feit dat 'n groot deel daarvan na Egipte saam met Jeremia en Barug geneem moes gewees het en vandaar weer in Babilonië moes beland het, in ag geneem moet word by enige mening oor die finale redaksie van die boek. Die neiging tot meer presiese datering van die tyd van Jeremia se uitsprake in die laaste uitbreiding wat aan na-eksiliese gebruik herinner, moes by die finale redaksie in Babilonië aangebring gewees het, miskien ná die ballingskap. 